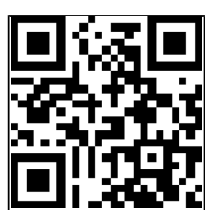

Editor's choice can to access mor free content

'Department of Physical Therapy, High Point University, High Point, North Carolina, USA

${ }^{2}$ Applied Neuromechanics Research Laboratory, Department of Kinesiology, University of North Carolina at Greensboro, Greensboro, North Carolina, USA

${ }^{3}$ Department of Mathematics and Statistics, University of North Carolina at Greensboro, Greensboro, North Carolina, USA

\section{Correspondence to}

Dr Jeffrey B Taylor, Department of Physical Therapy, High Point University, 833 Montlieu Avenue, High Point, NC 27262, USA; jtaylor@highpoint.edu

Accepted 8 July 2013 Published Online First 6 August 2013
CrossMark

To cite: Taylor JB,

Waxman JP, Richter SJ, et al. Br J Sports Med

2015:49:79-87.

\title{
Evaluation of the effectiveness of anterior cruciate ligament injury prevention programme training components: a systematic review and meta-analysis
}

Jeffrey B Taylor, ${ }^{1}{ }^{2}$ Justin P Waxman, ${ }^{2}$ Scott J Richter, ${ }^{3}$ Sandra J Shultz ${ }^{2}$

ABSTRACT

Background Anterior cruciate ligament $(A C L)$ injury prevention programmes have shown mixed results, which may be due to differing emphasis on training components. The purpose of this study was to (1) quantify the overall and relative duration of each training component encompassed within these programmes and (2) examine the effect of these durations on $\mathrm{ACL}$ injury rates.

Methods A systematic review was completed and meta-analyses performed on eligible studies to produce a pooled OR estimate of the effectiveness of these programmes. Meta-regression was used to detect any relationship that programme duration and the duration of individual training components had on $\mathrm{ACL}$ injury rates.

Results 13 studies were included for review. Results of the meta-analyses revealed a significant reduction of injuries after preventative training programmes for all ACL injuries (pooled OR estimate of $0.612,95 \% \mathrm{Cl}$ 0.44 to $0.85 ; p=0.004$ ) and for non-contact $A C L$ injuries (OR $0.351,95 \% \mathrm{Cl} 0.23$ to $0.54 ; \mathrm{p}<0.001$ ). Results of meta-regression analysis revealed that a greater duration of balance training was associated with a higher injury risk for $A C L$ injury $(p=0.04)$, while greater durations of static stretching was associated with a lower injury risk for non-contact ACL injuries $(p=0.04)$.

Conclusions While $\mathrm{ACL}$ prevention programmes are successful in reducing the risk of $A C L$ injury, the ideal combination and emphasis of training components within these programmes remains unclear. Evidence indicates that greater emphases on balance training and static stretching may be associated with an increase and decrease in injury risk, respectively.

\section{INTRODUCTION}

Partaking in recreational or competitive sports places participants at risk for athletic injuries, including ruptures of the anterior cruciate ligament (ACL). Up to $0.05 \%$ of the US population sustain ACL injuries each year, with the incidence being higher (3.67\%) in those who participate in multidirectional sports such as basketball and soccer. ${ }^{1}$ Among these injuries, $72 \%$ occur in non-contact situations. ${ }^{1}$ In 1999 , the cost associated with the subsequent treatment, diagnosis, surgery and rehabilitation was estimated at close to US\$12 000 per individual, and is assuredly higher at the present time. ${ }^{2}$ These costs did not account for time lost from activity (sport or work), psychological effects or long-term sequelae related to further joint pathology such as osteoarthritis, which has been found in $40-80 \%$ of individuals who suffer an ACL injury. ${ }^{3-6}$ Thus, preventing the initial trauma is considered the most efficient way to reduce the physical, psychological and financial costs associated with this devastating injury.

Multiple ACL prevention programmes have been developed with the goal of addressing modifiable risk factors for ACL injury that include abnormal biomechanical movement patterns ${ }^{7}$ and neuromuscular alterations. ${ }^{78}$ While a majority of these programmes target ACL injuries specifically, others attempt to globally reduce the incidence of lower extremity injuries. Women are the primary focus of these programmes, based on their injury rates being four times higher than their male counterparts. ${ }^{9}$ ACL injury prevention programmes vary widely in their framework and implementation methods, with a majority reporting successful reductions in injury rates ${ }^{10-19}$ while others have had less desirable outcomes. ${ }^{20-22}$ One reason for the range of effectiveness may be due to the fact that the duration and time span over which these programmes are administered vary considerably. Further, emphasis of various training components, including strength, agility, balance and plyometric training, vary widely in their prescribed duration and intensity.

To date, limited research has examined the volume and emphasis of the various training components to determine which components are most effective in reducing injury rates. Yoo $e t a l^{23}$ reported that programmes utilising strength and plyometric techniques were the most successful in reducing injuries, while programmes emphasising balance activities were unsuccessful. However, the authors did not state their methods for defining the individual components found in each programme and training volume was not accounted for in the analysis. In a recent meta-analysis, intervention effectiveness was reported to improve if athletes engaged in preventative training greater than $0.75 \mathrm{~h} / \mathrm{week}$, but did not delineate the emphasis of training components. ${ }^{24}$

To understand the volume of training requires knowledge of both the intensity as well as duration of each component. ${ }^{25}$ Unfortunately, the intensity of exercise is rarely reported in these studies. As such, an initial understanding of the type and duration of training components that yields the greatest reduction in injury risk may lend important insights into the relative emphasis of programme components, and the future development of prevention programmes. Thus, the primary purpose of this systematic review was to quantify the training duration of previously published prevention programmes, identify and quantify the duration of 
each individual training component, and analyse the efficacy of the various components in reducing ACL injury rates in female athletes. We focused specifically on female athletes, since the majority of programmes to date have targeted this population.

\section{METHODS}

\section{Study design}

A systematic review was performed in accordance with the PRISMA Statement for Reporting Systematic Reviews. ${ }^{26}$ No protocol exists for this study, which was exempt from review by the University's Institutional Review Board for the protection of the participants. No external funding supported this review.

\section{Search strategy}

An electronic search was performed on 31 July 2012 of the PubMed, MEDLINE, CINAHL, SPORTDiscus and the Cochrane Central Register of Controlled Trials databases. The search terms included: knee injur*(tiab), ACL injur*(tiab), and anterior cruciate ligament injur*(tiab) combined with the terms intervent*(tiab) and prevent*(tiab). Filters were utilised to access only those studies that investigated participants and were reported in English. No limitations were imposed on the date of publication.

\section{Eligibility criteria}

Studies were included if they met the following criteria: (1) the study design was a randomised controlled, or prospective cohort, trial, (2) the study reported ACL injury incidence, or made it possible to calculate these values for female athletes in both the intervention as well as control groups with the data provided, (3) the study published the specific exercises or components used in the intervention programme and (4) the study reported the duration of each individual training session. Authors of the studies that met some, but not all, of the criteria were contacted for further information and were included if the above details could be obtained.

\section{Study selection}

Two authors (JBT and JPW) independently reviewed the studies found during the database search. Articles were screened for eligibility based on review of the title and abstract only. If necessary, any disagreements were resolved by consensus with the third author (SJS). The full-text of included articles were then accessed and again analysed for eligibility. The same process was used to create consensus on articles to be included in the analysis after full-text review. Inter-rater agreement was calculated for both screening procedures using a Fleiss $\kappa$ with values interpreted as $<0$ poor agreement, 0.01-0.20 slight agreement, 0.21-0.40 fair agreement, 0.41-0.60 moderate agreement, $0.61-0.80$ substantial agreement and $0.81-1.0$ almost perfect agreement. ${ }^{27}$ Cited references of relevant articles were scanned and hand-searched for other possible inclusions to this study.

\section{Quality assessment}

Included studies were analysed using the Physiotherapy Evidence Database (PEDro) scale, which was developed from the Delphi list and used for quality assessment of the methodology of randomised clinical trials (http://www.pedro.org.au/ english/downloads/pedro-scale/). The scale exhibits moderate reliability (intraclass correlation $=0.56,95 \%$ CI 0.57 to 0.76 ) and helps to determine internal validity and identify studies with interpretable results. ${ }^{28}$ Two reviewers (JBT and JPW) independently assessed each study and where consensus was not reached the third reviewer (SJS) was consulted.
Data collection and analysis

The data extracted from each study included the training season, age of participants, presence or absence of technique-based feedback to athletes, minutes per training session, total number of training sessions, athletic exposures (AEs), player seasons (PSs), the duration and variety of training exercises used in the prevention programmes, and incidence rates of ACL injuries and non-contact ACL injuries. Training session times that were reported by each study were modified to better estimate actual training time by subtracting any reported rest periods, time for upper extremity exercises or simple warm-up jogging that did not focus on technique. If a range of time was given, the midpoint of the range was used for analysis. The total number of training sessions was calculated based on the frequency and duration of the intervention programme. In studies where no exact duration was stated, the length of the training was estimated based on reported calendar dates or the length of a typical season documented in other published studies. Total training time (TTT) was then found by multiplying the total number of training sessions by the number of minutes per training session and was reported in hours.

Each ACL prevention programme was analysed independently and the individual training activities were categorised into one of five components. Strength training was defined as an activity used to improve muscular strength through the use of resistance that included the use of bodyweight, free weights or strength machines. Activities were characterised as explosive if they utilised powerful movements, such as plyometric jumping or bounding. Balance exercises encompassed single-legged or double-legged stance activities that were designed to improve proprioceptive awareness. Agility exercises were defined as activities promoting the ability to move and change direction quickly and effectively, while under control. Finally, the stretching category included all static stretching activities.

After the specific activities were categorised in to one of the five components, training durations were then calculated. In this review, duration was defined as the time spent performing each exercise. The time spent in training in each component was independently estimated by two reviewers (JBT and JPW) based on the reported measures (time, reps, sets and percentage of programme). For example, the programme described by Walden et al ${ }^{18}$ incorporates six exercises (one-legged knee squat, pelvic lift, two-legged knee squat, bench, lunge and jump/landing) that were measured and reported in time or repetitions. The jump/landing was classified as a balance activity due to its focus on proprioceptive awareness, while the other five were considered to be strengthening exercises. The authors estimated that these six exercises took similar amounts of time to perform. Since each programme session lasted an average of $15 \mathrm{~min}, 5 / 6$ of the session duration was estimated for strengthening $(12.4 \mathrm{~min})$ and $1 / 6$ for balance training $(2.6 \mathrm{~min})$. The reviewers then compared their results and a consensus was reached if the estimates were within $10 \%$. If needed, the third reviewer was consulted (SJS), and in cases where no consensus was reached, the authors of references 20 and 29 were contacted. $^{20} 29$ The percentage time of each component in the programme was calculated by dividing the component time per session by the total time per session. TTT for each component was then computed by multiplying the appropriate percentage by the TTT to obtain the estimated total number of hours spent on each component for each intervention programme.

\section{Statistical analysis}

Study results were analysed using Comprehensive Meta Analysis, V.2.0 (Biostat, Englewood, New Jersey, USA) and SPSS, 
V.20 (IBM Corp, Armonk, New York, USA, 2011). In order to standardise injury rates for meta-analysis, and to include all studies, ORs were calculated in two forms: (1) based on AEs and (2) based on athlete PSs. AEs, which might be more correctly termed 'athlete participation', ${ }^{30}$ were reported as $\mathrm{AE}$ hours in some studies. AE hours were transformed to AEs based on the calculation of two exposure hours equals $1 \mathrm{AE}$. $\mathrm{AE}$ is the preferred reporting unit and this conversion has been used and calculated in other meta-analyses. ${ }^{30-32}$ PSs were determined by multiplying the number of athletes by the number of seasons in which injuries were tracked.

ORs were chosen as the metric to compute effect sizes because of its statistical properties that best match with meta-analysis procedures. $^{33}$ Seven studies dichotomised ACL injuries into contact and non-contact mechanisms, ${ }^{10-12}$ 15-18 three reported only non-contact injuries, ${ }^{13} \quad 14 \quad 20$ and three reported either contact and non-contact together or did not specify the nature of injury. ${ }^{21} 2229$ As such, ORs were computed and reported with $95 \%$ CI for (1) all ACL injuries in relation to
AEs (either unspecified injuries or contact plus non-contact injuries), (2) all ACL injuries in relation to PSs (either unspecified injuries or contact plus non-contact injuries), (3) all noncontact injuries in relation to AEs and (4) all non-contact injuries in relation to PSs.

Inverse variance meta-analyses, using a random effects model, were performed in order to compute the overall effect estimates of the four groups previously defined by OR calculations. A random effects model is used in cases where the true effect size may vary between studies and incorporates both between as well as within study heterogeneity into summary estimates. ${ }^{33}$ The 95\% CIs for the mean of the population of true ORs were calculated, with $\mathrm{p}<0.05$, indicating that the true OR was different from one. Both a $\chi^{2}$ statistic with corresponding $\mathrm{p}$ value, as well as an $\mathrm{I}^{2}$ statistic were calculated and used to describe the total variation across studies due to heterogeneity as opposed to random chance. Values of $\mathrm{I}^{2}$ of $25 \%$ are considered low, 50\% are considered moderate and $75 \%$ are considered high heterogeneity. ${ }^{34}$ Publication bias was assessed visually with funnel
Figure 1 Flow diagram of retrieved, screened and included studies.
Titles and abstracts retrieved $(\mathrm{n}=2235)$

- PubMed $(n=649)$

- Cochrane Registry of Trials $(n=271)$

- CINAHL/SPORTDISCUS $(n=1315)$

Removal of duplicates $(n=623)$

Titles and abstracts screened $(n=1612)$

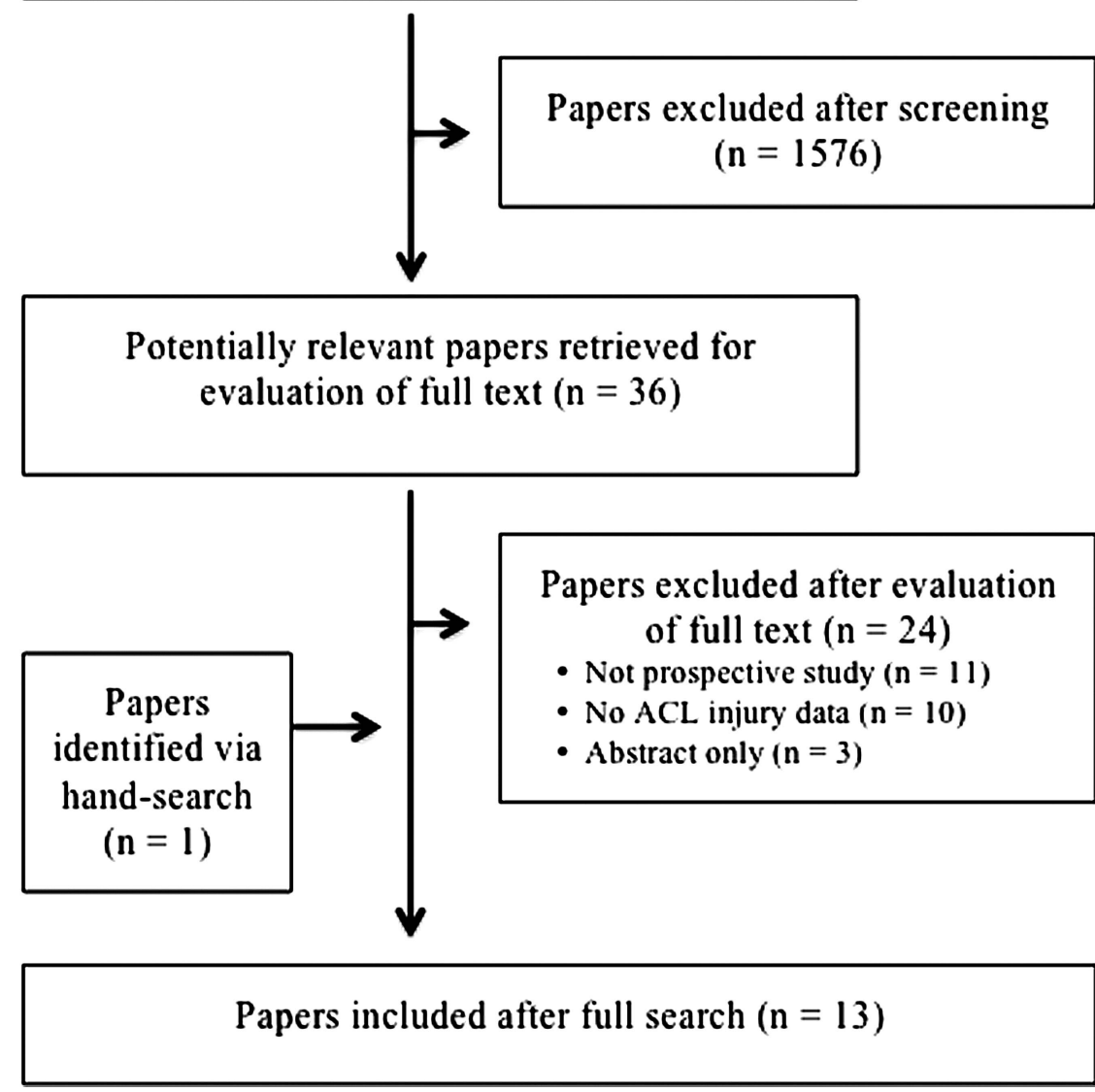


plots and quantified using Rosenthal's Fail-safe N, which determines how many potential missing studies would have to be included in order to make the overall estimate non-significant. ${ }^{3536}$

Meta-regression was used to analyse the extent to which total and individual programme components predicted the odds of becoming injured. General aspects of the programmes, including TTT and session duration were investigated, as were more specific variables of the training components, including their percentage of emphasis, session duration and total duration. Further, a subgroup analysis was performed to identify the effect of the presence or absence of technique feedback on injury risk. Owing to the low number of studies and power in these analyses, principal components analysis and meta-regression with multiple variables were not performed.

\section{RESULTS}

\section{Search results}

The electronic database search of PubMed, MEDLINE, CINAHL, SPORTDiscus and the Cochrane Register of
Controlled Trials yielded 2262 results. A flow diagram of the selection process is in figure 1. After duplicates were removed, 1612 studies remained. Of these, 1576 were excluded based on title and abstract review, leaving 36 for full text review ( $\kappa$ agreement $0.78,95 \%$ CI 0.65 to 0.89 ). The full text of the remaining studies were retrieved and reviewed for eligibility. Twenty-four of these studies were excluded because they either did not contain specific ACL incidence data, or did not document their intervention programme or were not a prospective study design ( $\kappa$ agreement $0.88,95 \%$ CI 0.71 to 1.0 ). An additional hand search revealed one study that met the inclusion criteria of this systematic review. ${ }^{22}$ Thirteen total studies were included in the final analysis. ${ }^{10-18} 20-2229$ Characteristics of these studies are in table 1 .

\section{Quality assessment}

Results of quality assessment using the PEDro scale showed a wide range of scores (3-8) with an average score of 4.5 (table 1). Not all studies that were included in this review were randomised controlled designs and subsequently had lower quality scores.

Table 1 Characteristics of studies included for review

\begin{tabular}{|c|c|c|c|c|c|c|c|}
\hline Study (year) & $\begin{array}{l}\text { PEDro } \\
\text { score }\end{array}$ & $\begin{array}{l}\text { Number of } \\
\text { participants, } \\
\text { T and UT }\end{array}$ & $\begin{array}{l}\text { Age of } \\
\text { participants } \\
\text { (years) }\end{array}$ & $\begin{array}{l}\text { Time/training } \\
\text { session (min) }\end{array}$ & $\begin{array}{l}\text { Total number of prescribed } \\
\text { training sessions }\end{array}$ & $\begin{array}{l}\text { Total } \\
\text { training } \\
\text { time }(h)\end{array}$ & Feedback \\
\hline Gilchrist et al (2008) & 4 & $\begin{array}{l}\text { T } 583 \\
\text { UT } 852\end{array}$ & 19.9 (mean) & $19 *$ & 36 ( $3 \times /$ week for 12 weeks) & 11.4 & Yes \\
\hline Heidt et al (2000) & 4 & $\begin{array}{l}\text { T } 42 \\
\text { UT } 258\end{array}$ & 14-18 (range) & 43.5 & $\begin{array}{l}30 \text { (12 treadmill, } 12 \text { strength training, } \\
6 \text { plyometric) } \ddagger \ddagger\end{array}$ & 21.8 & No \\
\hline Hewett et al (1999) & 3 & $\begin{array}{l}\text { T } 366 \\
\text { UT } 463\end{array}$ & 14-18 (range) & $44.7 \dagger$ & 18 (3×/week for 6 weeks) & 13.4 & Yes \\
\hline Kiani et al (2010) & 4 & $\begin{array}{l}\text { T } 777 \\
\text { UT } 729\end{array}$ & 13-17 (range) & $15 \ddagger$ & $\begin{array}{l}51 \text { ( } 24 \text { preseason at } 2 \times / \text { week for } \\
12 \text { weeks, } 27 \text { inseason at } 1 \times / \text { week for } \\
27 \text { weeks) }\end{array}$ & 12.8 & Yes \\
\hline LaBella et al (2011) & 5 & $\begin{array}{l}\text { T } 737 \\
\text { UT } 755\end{array}$ & $\begin{array}{l}\text { C: } 16.2 \pm 1.1 \\
\text { (mean) } \\
\text { I: } 16.2 \pm 1.5 \\
\text { (mean) }\end{array}$ & $19 * \S$ & 43 (3.3 practices/week for 13 weeks) & 13.6 & Yes \\
\hline $\begin{array}{l}\text { Mandelbaum et al } \\
\text { (2005) }\end{array}$ & 3 & $\begin{array}{l}\text { T } 1885 \\
\text { UT } 3818\end{array}$ & 14-18 (range) & $19^{*}$ & 36 (3x/week for 12 weeks) & 11.4 & No \\
\hline Myklebust et al (2005) & 3 & $\begin{array}{l}\text { T } 1705 \\
\text { UT } 942\end{array}$ & $21-22$ (mean) & 15 & $\begin{array}{l}55 \text { (18 preseason at } 3 \times / \text { week for } \\
6 \text { weeks, } 37 \text { inseason at } 1 \times / \text { week for } \\
37 \text { weeks) }\end{array}$ & 13.8 & Yes \\
\hline Olsen et al (2005) & 7 & $\begin{array}{l}\text { T } 958 \\
\text { UT } 879\end{array}$ & 16-17 (mean) & 18 & $\begin{array}{l}45 \text { (15 consecutive }(3 \times / \text { week for } \\
5 \text { weeks), estimated } 30 \text { inseason at } 1 \times 1 \\
\text { week for } 30 \text { weeks) }\end{array}$ & 13.5 & Yes \\
\hline Petersen et al (2005) & 3 & $\begin{array}{l}\text { T } 134 \\
\text { UT } 142\end{array}$ & $\begin{array}{l}\text { C: } 19.8 \text { (med) } \\
\text { I: } 19.4 \text { (med) }\end{array}$ & 10 & $\begin{array}{l}59 \text { ( } 24 \text { preseason at } 3 \times / \text { week for } \\
8 \text { weeks, } 35 \text { inseason at } 1 \times / \text { week for } \\
\text { estimated } 35 \text { weeks) }{ }^{* *}\end{array}$ & 9.8 & Yes \\
\hline Pfeiffer et al (2006) & 3 & $\begin{array}{l}\text { T } 577 \\
\text { UT } 862\end{array}$ & 14-18 (range) & 20 & $30(2 \times /$ week for estimated 15 weeks $)+\dagger$ & 10.0 & No \\
\hline Soderman et al (2000) & 4 & $\begin{array}{l}\text { T } 62 \\
\text { UT } 78\end{array}$ & $\begin{array}{l}\text { C: } 20.4 \pm 4.6 \\
\text { I: } 20.5 \pm 5.4\end{array}$ & 12.5 & $\begin{array}{l}108 \text { ( } 30 \text { consecutive, } 78 \text { inseason at } 3 \times 1 \\
\text { week for } 26 \text { weeks) }\end{array}$ & 22.5 & No \\
\hline Steffen et al (2008) & 8 & $\begin{array}{l}\text { T } 1073 \\
\text { UT } 947\end{array}$ & 15.4 (med) & 15 & $\begin{array}{l}40 \text { (15 consecutive sessions, then } 25 \\
\text { inseason } 1 \times / \text { week for } 25 \text { weeks) }\end{array}$ & 10.0 & Yes \\
\hline Walden et al (2012) & 7 & $\begin{array}{l}\text { T } 2479 \\
\text { UT } 2085\end{array}$ & 12-17 (range) & 15 & 60 (2×/week for 30 weeks $)$ & 15.0 & Yes \\
\hline
\end{tabular}

* Removed 1 min jog from 20 min total programme.

tRemoved 15 min rest break, 2 min cool down, 13.3 min upper extremity exercises from 75 min total programme.

łremoved 5 min jogging from 20 min total programme.

$\S$ did not include modified training sessions prior to games.

Ibased on Gilchrist et al. ${ }^{10}$

** estimated season length based on Myklebust and colleagues ${ }^{16}$.

t†estimated high school sport season length.

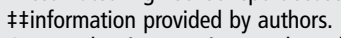

C, control; I, intervention; med, median; PEDro, Physiotherapy Evidence Database; T, trained; UT, untrained. 
Further, no studies were able to blind the participants or interventionists, which further reduced scores.

\section{Overall intervention effects}

Meta-analysis results revealed a statistically significant reduction in all ACL injuries (OR $0.61,95 \%$ CI 0.44 to 0.85 ) and noncontact ACL injuries (OR 0.35 , 95\% CI 0.23 to 0.54 ) when incidence was expressed relative to PSs (figure 2A,B). Similar effect estimates were obtained when incidence was expressed relative to AEs for all ACL injuries (OR 0.64, 95\% CI 0.42 to 0.99 and non-contact ACL injuries (OR 0.38 , 95\% CI 0.22 to $0.64)$. Because of this, and because more studies were included when injury risk was expressed relative to PSs, only the injury risk data based on PSs were examined in the meta-regression and subgroup analyses.

\section{Heterogeneity}

The $\chi^{2}$ statistic for all meta-analyses was not statistically significant and $\mathrm{I}^{2}$ calculations ranged from $0 \%$ to $28 \%$, which is considered to have a low effect from heterogeneity. Since these values were found to be non-significant, further statistical analysis to explain the heterogeneity was not pursued.

\section{Publication bias}

Funnel plots depicted asymmetry in the lower right region, indicating that results may have some bias due to the lack of inclusion of small studies with insignificant findings that have been unpublished or not found by our search strategies. However, two separate Classic Fail-safe $\mathrm{N}$ tests show that the number of studies needed to be included to change the results of the meta-analyses to non-significant were 55 for the non-contact ACL injury analysis and 12 for the unspecified/total ACL injury analysis.

\section{Total training duration}

Total programme training duration can be found in table 1 . The frequency of training sessions ranged from once per week to daily; in some cases, training frequency was reduced during the transition of the programme from a training phase to a maintenance phase. The duration of a single training session ranged from 10 to $44.7 \mathrm{~min}$, while the total number of training sessions ranged from 10 to 108 . Taken together, this represents a wide variety of TTTs ranging from 9.8 to $22.5 \mathrm{~h}$. Results from the meta-regression analysis revealed no statistically significant effect of TTT or session duration on ACL injury rates (table 2).

\section{Training components}

Table 3 reports the results for the duration of each programme component in terms of per cent emphasis, time per training session and total time. Strength, explosive and agility training were each represented in $69 \%$ of the programmes, where balance training and static stretching were represented in 54\% and $23 \%$ of programmes, respectively. The training emphasis (defined as the component with the highest percentage of total duration) varied considerably between programmes, with most programmes having the greatest emphasis on balance and agility training. Meta-regression resulted in two statistically significant findings (table 2). Results show that ACL injury risk increases as the total duration of balance training increases $(p=0.04$; figure 3$)$, whereas injury risk decreases with a greater emphasis and longer duration of prescribed static stretching $(\mathrm{p}=0.04)$.
A

\section{Study name Odds ratio and $95 \% \mathrm{Cl}$}

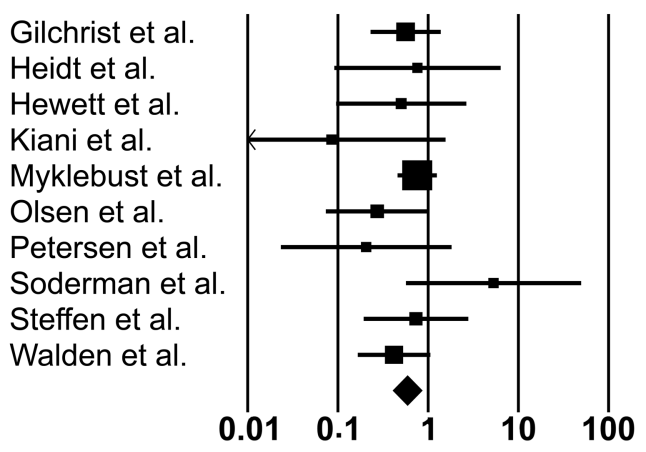

B

\section{Study name Odds ratio and $95 \% \mathrm{Cl}$}

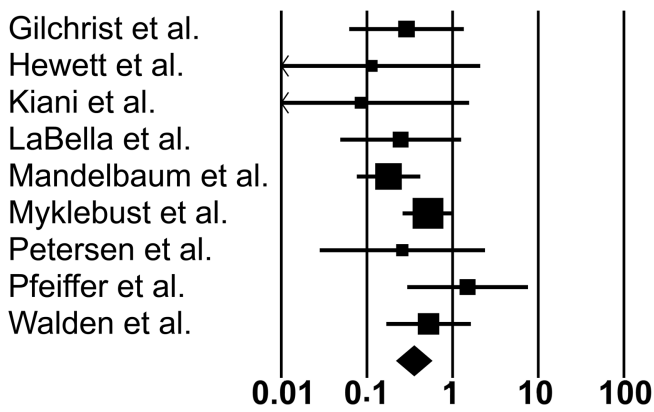

Figure 2 Meta-analysis forest plot of $(A)$ total anterior cruciate ligament $(A C L)$ injuries and $(B)$ non-contact $A C L$ injuries in relation to player seasons. Favours $A$ indicates reduction in injury risk and favours $B$ indicates heightened injury risk.

\section{Technique feedback}

For non-contact ACL injuries, a subgroup analysis demonstrated that there was no statistical difference between those that received feedback and those that did not $(p=0.74)$. The same subgroup analysis performed in the total ACL injury group also yielded non-statistically significant results $(p=0.13)$.

\section{DISCUSSION}

Results of these meta-analyses indicate that injury prevention programmes can be successful in reducing ACL injuries in female athletes. These results are consistent with prior findings ${ }^{23} 243237$ and suggest that continued research efforts aimed at improving the efficiency and efficacy of these preventative training programmes are warranted. Moreover, results suggest that these programmes may have a stronger effect on the reduction of injury risk for non-contact ACL injuries compared with those resulting from a contact mechanism. Though further meta-regression analyses provided no statistically significant findings on the frequency or durations of these programmes, trends were found with respect to individual training programme components that may help the development of future preventative programmes.

As described in this review, intervention programmes vary widely in their design and implementation. However, meta-regression results did not reveal any clear trend that allows for recommendations of duration parameters for training components of future intervention designs. The lack of significance may be due to a lack of power in the statistical analysis from the small sample size or high variability of included studies. 
Table 2 Results of meta-regression with significance set at $p<0.05$ level

\begin{tabular}{|c|c|c|c|c|c|c|}
\hline & \multicolumn{3}{|c|}{ All ACL injuries } & \multicolumn{3}{|c|}{ Non-contact $\mathrm{ACL}$ injuries } \\
\hline & Slope & $95 \% \mathrm{Cl}$ & $\mathrm{p}$ Value & Slope & $95 \% \mathrm{Cl}$ & $\mathrm{p}$ Value \\
\hline \multicolumn{7}{|l|}{ General characteristics } \\
\hline TTT & 0.096 & -0.04 to 0.24 & 0.18 & 0.020 & -0.29 to 0.33 & 0.90 \\
\hline Minutes/session & -0.003 & -1.41 to 0.46 & 0.91 & -0.046 & -0.14 to 0.04 & 0.32 \\
\hline \multicolumn{7}{|l|}{ Strength training } \\
\hline Percentage of emphasis & -0.009 & -0.02 to 0.003 & 0.15 & -0.002 & -0.02 to 0.01 & 0.80 \\
\hline Minutes/session & -0.042 & -0.11 to 0.02 & 0.21 & -0.033 & -0.14 to 0.08 & 0.55 \\
\hline Total duration & -0.055 & -0.13 to 0.02 & 0.18 & -0.005 & -0.12 to 0.11 & 0.93 \\
\hline \multicolumn{7}{|l|}{ Explosive training } \\
\hline Percentage of emphasis & 0.003 & -0.02 to 0.03 & 0.80 & 0.016 & -0.01 to 0.04 & 0.18 \\
\hline Minutes/session & 0.011 & -0.06 to 0.09 & 0.78 & 0.069 & -0.05 to 0.19 & 0.25 \\
\hline Total duration & 0.030 & -0.12 to 0.18 & 0.70 & 0.160 & -0.07 to 0.39 & 0.17 \\
\hline \multicolumn{7}{|l|}{ Balance training } \\
\hline Percentage of emphasis & 0.010 & -0.002 to 0.02 & 0.09 & 0.009 & -0.004 to 0.02 & 0.17 \\
\hline Minutes/session & 0.065 & -0.01 to 0.14 & 0.11 & 0.063 & -0.03 to 0.15 & 0.17 \\
\hline Total duration & 0.076 & 0.004 to 0.15 & $0.04^{*}$ & 0.070 & -0.03 to 0.17 & 0.16 \\
\hline \multicolumn{7}{|l|}{ Agility training } \\
\hline Percentage of emphasis & -0.007 & -0.03 to 0.02 & 0.55 & -0.020 & -0.04 to 0.004 & 0.09 \\
\hline Minutes/session & -0.041 & -0.16 to 0.08 & 0.51 & -0.106 & -0.23 to 0.02 & 0.09 \\
\hline Total duration & -0.059 & -0.25 to 0.13 & 0.53 & -0.167 & -0.36 to 0.03 & 0.10 \\
\hline \multicolumn{7}{|l|}{ Static stretching } \\
\hline Percentage of emphasis & -0.003 & -0.03 to 0.02 & 0.82 & -0.031 & -0.06 to -0.001 & $0.04^{*}$ \\
\hline Minutes/session & -0.009 & -0.08 to 0.07 & 0.82 & -0.100 & -0.21 to 0.01 & 0.07 \\
\hline Total duration & -0.026 & -0.24 to 0.19 & 0.82 & -0.263 & -0.52 to -0.01 & $0.04^{*}$ \\
\hline
\end{tabular}

Results are organised by general characteristics of the programme (TTT and session duration) and training component (percentage of emphasis of component in relation to duration of session, duration of time spent in that training component per session and total duration of that training component throughout the programme).

$\mathrm{ACL}$, anterior cruciate ligament; TTT, total training time.

Prospective injury prevention studies are challenging because of the resources that are needed. Only 13 studies on ACL injury prevention programmes that met our inclusion criteria have been previously published. Further, variability in the results may have stemmed from the variety of prevention programme designs or the diversity of sports, ages and athletes targeted in these studies. Thus, future studies of ACL injury prevention programmes will help to improve statistical power and hopefully provide more convincing evidence to help shape future prevention efforts.

While specific duration and emphasis recommendations cannot be made as a result of these analyses, the overarching theme is that some form of prevention training is better than nothing; however, the composition and duration of the optimal prevention programme is still unknown. Larger amounts of balance training were found to be unsuccessful in reducing ACL injury rates and statistical tests showed that increasing the total duration of balance training increased the OR of injury $(p=0.04)$. Yoo et $a l^{23}$ found comparable results in regard to balance training. In their subgroup analysis, the inclusion of balance training yielded an OR that was not statistically significant (OR $0.63,95 \%$ CI 0.37 to 1.09 ), while programmes without balance training showed a statistically significant OR lowering injury risk (OR 0.27 , 95\% CI 0.14 to 0.49). Similarly, Sadoghi et $a l^{37}$ found no evidence of effectiveness from the use of a balance board during prevention programmes $(p=0.712)$. However, these findings conflict with previous research that shows positive outcomes on at-risk lower extremity mechanics as a result of balance and proprioceptive training. ${ }^{38}$ After closer investigation of the balance training protocol used in the study by Myer et $a l^{38}$ appreciably higher durations and intensities were used when compared with balance training components of ACL prevention programmes, suggesting that for balance training to be more efficacious, prevention programmes may need to intensify their balance training prescription.

Further, time spent in balance training may have limited the opportunity for clinicians or teammates to provide valuable feedback in regards to movement patterns and neuromuscular control during more dynamic functional activities. Various types of feedback, including visual and verbal, have been shown to reduce abnormal biomechanics associated with ACL injury risk. ${ }^{39-41}$ However, results of our subgroup analysis show no significant effect of the presence of technique training or feedback on non-contact $(p=0.74)$ or total $(p=0.13)$ ACL injury risk. The type and amount of feedback varied widely between the programmes included in this review. Some programmes predominantly utilised skilled sports medicine clinicians to provide instruction, ${ }^{10} 11 \quad 17$ while others used coaches or teammates. $^{12} 1315161822$ Inconsistent with our findings, other systematic reviews ${ }^{32} 42$ have found that feedback for technique training may be a valuable element of prevention programmes. We encourage authors to detail the amount and type of feedback in future studies so that their potential effects on injury risk reduction can be better elucidated.

Though static stretching has been a controversial topic in regard to injury prevention, ${ }^{43}$ meta-regression analysis shows that static stretching may have a positive impact on reducing injury rates when performed in an ACL prevention programme. Previous studies have found that static stretching has no overall impact on preventing general musculoskeletal athletic injuries, but may have some relationship with reducing ligamentous injuries. $^{43} 44$ Static stretching may provide a means for ACL 
Table 3 Programme components of ACL prevention programmes with intended training time

\begin{tabular}{|c|c|c|c|c|c|c|c|c|c|c|c|c|c|c|c|c|c|}
\hline \multirow[b]{2}{*}{ Study (year) } & \multirow[b]{2}{*}{$\begin{array}{l}\text { Minutes/ } \\
\text { session }\end{array}$} & \multirow[b]{2}{*}{ TTT } & \multicolumn{3}{|c|}{ LE/core strength } & \multicolumn{3}{|c|}{ Explosive } & \multicolumn{3}{|c|}{ Balance } & \multicolumn{3}{|c|}{ Agility } & \multicolumn{3}{|c|}{ Stretch } \\
\hline & & & $\begin{array}{l}\text { Per } \\
\text { cent }\end{array}$ & $\begin{array}{l}\text { Minutes/ } \\
\text { session }\end{array}$ & $\begin{array}{l}\text { Total } \\
\text { hours }\end{array}$ & $\begin{array}{l}\text { Per } \\
\text { cent }\end{array}$ & $\begin{array}{l}\text { Minutes/ } \\
\text { session }\end{array}$ & $\begin{array}{l}\text { Total } \\
\text { hours }\end{array}$ & $\begin{array}{l}\text { Per } \\
\text { cent }\end{array}$ & $\begin{array}{l}\text { Minutes/ } \\
\text { session }\end{array}$ & $\begin{array}{l}\text { Total } \\
\text { hours }\end{array}$ & $\begin{array}{l}\text { Per } \\
\text { cent }\end{array}$ & $\begin{array}{l}\text { Minutes/ } \\
\text { session }\end{array}$ & $\begin{array}{l}\text { Total } \\
\text { hours }\end{array}$ & $\begin{array}{l}\text { Per } \\
\text { cent }\end{array}$ & $\begin{array}{l}\text { Minutes/ } \\
\text { session }\end{array}$ & $\begin{array}{l}\text { Total } \\
\text { hours }\end{array}$ \\
\hline $\begin{array}{l}\text { Gilchrist et al } \\
\text { (2008) }\end{array}$ & 19 & 11.4 & 15.8 & 3.0 & 1.8 & 15.8 & 3.0 & 1.8 & 0 & 0 & 0 & 42.1 & 8.0 & 4.8 & 26.3 & 5.0 & 3.0 \\
\hline Heidt et al (2000) & 43.5 & 21.8 & 34.5 & 15.0 & 7.5 & 65.5 & 28.5 & 14.3 & 0 & 0 & 0 & 0 & 0 & 0 & 0 & 0 & 0 \\
\hline Hewett et al (1999) & 44.7 & 13.4 & 23.9 & 10.7 & 3.2 & 21.3 & 9.5 & 2.8 & 0 & 0 & 0 & 4.5 & 2 & 0.6 & 50.3 & 22.5 & 6.7 \\
\hline Kiani et al (2010) & 15 & 12.8 & 60.0 & 9.0 & 7.7 & 0 & 0 & 0 & 13.3 & 2.0 & 1.7 & 26.7 & 4.0 & 3.4 & 0 & 0 & 0 \\
\hline LaBella et al (2011) & 19 & 13.6 & 23.2 & 4.4 & 3.1 & 25.8 & 4.9 & 3.5 & 0 & 0 & 0 & 51.0 & 9.7 & 6.9 & 0 & 0 & 0 \\
\hline $\begin{array}{l}\text { Mandelbaum et al } \\
\text { (2005) }\end{array}$ & 19 & 12.0 & 15.8 & 3.0 & 1.8 & 15.8 & 3.0 & 1.8 & 0 & 0 & 0 & 42.1 & 8.0 & 4.8 & 26.3 & 5.0 & 3.0 \\
\hline $\begin{array}{l}\text { Myklebust et al } \\
\text { (2005) }\end{array}$ & 15 & 13.8 & 0 & 0 & 0 & 16.7 & 2.5 & 2.3 & 66.7 & 10 & 9.2 & 16.7 & 2.5 & 2.3 & 0 & 0 & 0 \\
\hline Olsen et al (2005) & 18 & 13.5 & 25.0 & 4.5 & 3.4 & 0 & 0 & 0 & 25.0 & 4.5 & 3.4 & 50.0 & 9.0 & 6.8 & 0 & 0 & 0 \\
\hline $\begin{array}{l}\text { Petersen et al } \\
(2005)\end{array}$ & 10 & 9.8 & 0 & 0 & 0 & 50.0 & 5.0 & 4.9 & 50.0 & 5.0 & 4.9 & 0 & 0 & 0 & 0 & 0 & 0 \\
\hline Pfeiffer et al (2006) & 20 & 10.0 & 0 & 0 & 0 & 75.0 & 15.0 & 7.5 & 0 & 0 & 0 & 25.0 & 5.0 & 2.5 & 0 & 0 & 0 \\
\hline $\begin{array}{l}\text { Soderman et al } \\
(2000)\end{array}$ & 12.5 & 22.5 & 0 & 0 & 0 & 0 & 0 & 0 & 100.0 & 12.5 & 22.5 & 0 & 0 & 0 & 0 & 0 & 0 \\
\hline Steffen et al (2008) & 15 & 10.0 & 20.0 & 3.0 & 2.0 & 30.0 & 4.5 & 3.0 & 36.7 & 5.5 & 3.7 & 13.3 & 2.0 & 1.3 & 0 & 0 & 0 \\
\hline $\begin{array}{l}\text { Walden et al } \\
\text { (2012) }\end{array}$ & 15 & 15.0 & 82.7 & 12.4 & 12.4 & 0 & 0 & 0 & 17.3 & 2.6 & 2.6 & 0 & 0 & 0 & 0 & 0 & 0 \\
\hline
\end{tabular}

$\mathrm{ACL}$, anterior cruciate ligament; $\mathrm{LE}$, lower extremity; $\mathrm{TTT}$, total training time. 
Figure 3 Meta-regression results of total balance training duration. Each circle represents an included study with the size consistent with the weight assigned during meta-analysis. A regression line is seen, indicating a less protective $\mathrm{OR}$ as total balance duration increases.

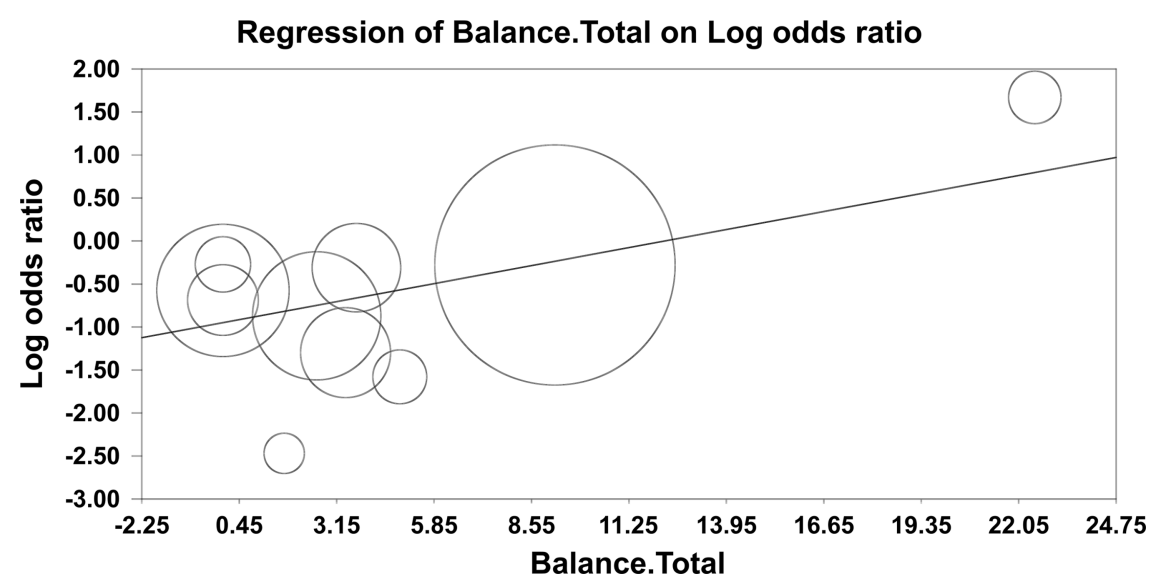

injury reduction by improving muscle imbalance or beneficially modifying the structural properties of ligamentous tissues. Cautious interpretation of these meta-regression findings is warranted, as only three of the analysed studies included static stretching in their prevention programmes. Future studies comparing static and dynamic flexibility programmes may be warranted to determine whether the benefits are derived from improved joint range of motion and flexibility or if the technique used to obtain these effects varies based on the implementation method. Any dynamic flexibility components in these programmes were captured as agility exercises based on their ability to promote controlled change of directions.

Other findings, while not statistically significant, are worth noting as they may help guide further research and development of future programmes. Increasing strength training emphasis $(p=0.15)$ and duration $(p=0.18)$ suggest this component may also prove useful in reducing total ACL injury rates. The purpose of including strength training as a component in these programmes is based on the premise that women lack adequate strength to control the alignment of the lower extremity during sport-specific activities. However, after careful review of these prevention programmes, it became apparent that common strength training guidelines, which call for progressive overload, were often lacking in these programmes. As such, the outcomes of these strengthening components may have been limited to more neural adaptations rather than physiological changes in muscle characteristics. ${ }^{25}$ Given the results of this meta-regression, future research is warranted to examine whether more aggressive or longer term strength training exercises would further impact injury risk reduction.

Increasing the emphasis $(p=0.09)$ and duration $(p=0.10)$ of agility training also showed evidence that this type of training may be beneficial in reducing non-contact ACL injury rates. A 6-week agility training protocol has been shown to improve medial hamstring activation patterns in side-step pivot manoeuvres, which may reduce ACL injury risk. ${ }^{45}$ Timing of the agility training intervention may be important as lower extremity mechanics in landing and cutting tasks are negatively altered after a fatigue-producing agility training programme. ${ }^{46}$ More research on the effects of agility training on ACL injury incidence may provide stronger evidence to support these claims.

In addition to strength and agility training, plyometric or explosive training was the most commonly used training component in the ACL prevention programmes included in this review. Though the demands and intended outcomes of these exercises are more likely to resemble sport-specific demands, evidence to support the superiority of these exercises in reducing injury risk was insufficient. This was surprising, considering the positive effects that this type of training can have on altered lower extremity mechanics. ${ }^{47-50}$ However, the extent to which effectively modifying at-risk biomechanics is able to reduce ACL injuries has not yet been determined. Moreover, the principles that govern programme implementation may also deserve further attention. For example, many of the preventative programmes were administered to young athletes without also including a foundational strength base. This strength foundation is considered to be critical before progressing to more explosive activities $^{25}$ and may represent an important component to include for maximising effectiveness.

\section{Limitations}

This systematic review and meta-analysis was subject to limitations based on the quantity and quality of previously published programmes and the variety of reporting mechanisms of each prevention programme. Calculations and analyses were based on the prescribed prevention programme, as opposed to what the participants actually performed. With compliance rates as low as $26 \%{ }^{32}$ the prescribed versus actual volumes may be very different and could have notably influenced the results. Low compliance leads to lower amounts of training volume, which may influence a programme's effectiveness. Another limitation of this analysis involves the interpretation of training duration. Studies included in this review reported training duration in a variety of units (ie, time and repetitions). Time was the most consistent measurement unit and was therefore used as the definition of training duration in this review. While we fully acknowledge that training volume may be a more practical measure based on the inclusion of intensity in its definition, there was insufficient information reported in these studies to account for intensity in volume calculations. Quantifying the intensity of these programmes may be a critical piece in understanding the relative contributions of each component to injury-risk reduction and what level of stimulus is needed to affect a positive change, and is therefore an important direction of future research and exercise prescription. We strongly encourage future publications to be as explicit as possible in the prescription of their prevention programme relative to intensity, duration and frequency in order to better understand the relative benefit of each component.

Further, we placed each exercise in only one of five categories, though some complex exercises may serve multiple purposes. The optimal prevention strategy may very well be a comprehensive approach, incorporating multiple training components combined into one programme. Because of the small 
number of studies that were included in this analysis, and therefore low statistical power, training components could not be grouped together to conduct a multivariate statistical analysis. As additional studies are published, interactions between these components may be better delineated and more concrete recommendations for preventative training can be established. On the basis of this review, we recommend that future studies carefully consider and clearly report training methodology (duration, intensity and progression) consistent with current evidencebased strength and conditioning guidelines.

\section{CONCLUSION}

While ACL prevention programmes are effective in reducing the risk of injury in female athletes, the ideal composition of these programmes remains elusive.

Consistent with previous analyses, the effectiveness of ACL prevention programmes may improve as balance training is de-emphasised and static stretching is emphasised. However, given the small number of studies, and the lack of detail regarding the intensity, etc, of various components, considerably more work is needed to determine which combination of programme components, and the duration and intensity at which they are delivered are most effective at reducing injury risk. Further research will help shape future prevention efforts, as more information regarding volume and training emphasis is uncovered.

Contributors JBT participated in study design, electronic and hand searches, study selection, quality assessment, data extraction, and drafted and revised the manuscript. JPW participated in electronic and hand searches, data collection and drafted and revised the manuscript. SJR helped in study design, statistical analysis, and drafted and revised the manuscript. SJS participated in study design, study selection, data collection, and drafted and revised the manuscript.

\section{Competing interests None.}

Provenance and peer review Not commissioned; externally peer reviewed.

\section{REFERENCES}

1 Moses B, Orchard J, Orchard J. Systematic review: annual incidence of ACL injury and surgery in various populations. Res Sports Med 2012;20:157-79.

2 Gottlob CA, Baker CL Jr, Pellissier JM, et al. Cost effectiveness of anterior cruciate ligament reconstruction in young adults. Clin Orthop Relat Res 1999;367:272-82.

3 Indelicato PA, Bittar ES. A perspective of lesions associated with ACL insufficiency of the knee. A review of 100 cases. Clin Orthop Relat Res 1985;198:77-80.

4 McDaniel WJ, Dameron TB. The untreated anterior cruciate ligament rupture. Clin Orthop Relat Res 1983;172:158-63.

5 Neyret P, Donell ST, Dejour H. Results of partial meniscectomy related to the state of the anterior cruciate ligament. Review at 20 to 35 years. J Bone Joint Surg Br 1993;75:36-40.

6 Sutherland AG, Cooper K, Alexander LA, et al. The long-term functional and radiological outcome after open reconstruction of the anterior cruciate ligament. J Bone Joint Surg Br 2010;92:1096-9.

7 Hewett TE, Myer GD, Ford KR, et al. Biomechanical measures of neuromuscular control and valgus loading of the knee predict anterior cruciate ligament injury risk in female athletes: a prospective study. Am I Sports Med 2005;33:492-501.

8 Alentorn-Geli E, Myer GD, Silvers HJ, et al. Prevention of non-contact anterior cruciate ligament injuries in soccer players. Part 1: mechanisms of injury and underlying risk factors. Knee Surg Sports Traumatol Arthrosc 2009;17:705-29.

9 Arendt E, Dick R. Knee injury patterns among men and women in collegiate basketball and soccer. NCAA data and review of literature. Am I Sports Med 1995;23:694-701.

10 Gilchrist J, Mandelbaum BR, Melancon $\mathrm{H}$, et al. A randomized controlled trial to prevent noncontact anterior cruciate ligament injury in female collegiate soccer players. Am J Sports Med 2008;36:1476-83.

11 Hewett TE, Lindenfeld TN, Riccobene JV, et al. The effect of neuromuscular training on the incidence of knee injury in female athletes. A prospective study. Am J Sports Med 1999;27:699-706

12 Kiani $A$, Hellquist $E$, Ahlqvist $K$, et al. Prevention of soccer-related knee injuries in teenaged girls. Arch Intern Med 2010;170:43-9.

13 LaBella CR, Huxford MR, Grissom J, et al. Effect of neuromuscular warm-up on injuries in female soccer and basketball athletes in urban public high schools: cluster randomized controlled trial. Arch Pediatr Adolesc Med 2011;165:1033-40.
14 Mandelbaum BR, Silvers HJ, Watanabe DS, et al. Effectiveness of a neuromuscular and proprioceptive training program in preventing anterior cruciate ligament injuries in female athletes: 2-year follow-up. Am J Sports Med 2005;33:1003-10.

15 Myklebust G, Engebretsen L, Braekken IH, et al. Prevention of anterior cruciate ligament injuries in female team handball players: a prospective intervention study over three seasons. Clin J Sport Med 2003:13:71-8.

16 Olsen $\mathrm{OE}$, Myklebust $\mathrm{G}$, Engebretsen $\mathrm{L}$, et al. Exercises to prevent lower limb injuries in youth sports: cluster randomised controlled trial. BMJ 2005;330:449.

17 Petersen W, Braun C, Bock W, et al. A controlled prospective case control study of a prevention training program in female team handball players: the German experience. Arch Orthop Trauma Surg 2005;125:614-21.

18 Walden M, Atroshi I, Magnusson H, et al. Prevention of acute knee injuries in adolescent female football players: cluster randomised controlled trial. BMJ 2012;344:e3042.

19 Caraffa A, Cerulli G, Projetti M, et al. Prevention of anterior cruciate ligament injuries in soccer. A prospective controlled study of proprioceptive training. Knee Surg Sports Traumatol Arthrosc 1996:4:19-21.

20 Pfeiffer RP, Shea KG, Roberts D, et al. Lack of effect of a knee ligament injury prevention program on the incidence of noncontact anterior cruciate ligament injury. J Bone Joint Surg Am 2006;88:1769-74.

21 Soderman K, Werner S, Pietila T, et al. Balance board training: prevention of traumatic injuries of the lower extremities in female soccer players? A prospective randomized intervention study. Knee Surg Sports Traumatol Arthrosc 2000;8:356-63.

22 Steffen K, Myklebust G, Olsen OE, et al. Preventing injuries in female youth football—a cluster-randomized controlled trial. Scand I Med Sci Sports 2008;18:605-14

$23 \mathrm{Yoo} \mathrm{JH}$, Lim BO, Ha M, et al. A meta-analysis of the effect of neuromuscular training on the prevention of the anterior cruciate ligament injury in female athletes. Knee Surg Sports Traumatol Arthrosc 2010;18:824-30.

24 Gagnier JJ, Morgenstern H, Chess L. Interventions designed to prevent anterior cruciate ligament injuries in adolescents and adults: a systematic review and meta-analysis. Am J Sports Med 2012. Published Online First: 12 September 2012.

25 Baechle TR, Earle RW. Essentials of strength and conditioning. 2nd edn. Champaign, IL: Human Kinetics, 2000:15-24,427-440.

26 Liberati A, Altman DG, Tetzlaff J, et al. The PRISMA statement for reporting systematic reviews and meta-analyses of studies that evaluate health care interventions: explanation and elaboration. PLoS Med 2009;6:e1000100.

27 Landis JR, Koch GG. The measurement of observer agreement for categorical data. Biometrics 1977;33:159-74.

28 Maher CG, Sherrington C, Herbert RD, et al. Reliability of the PEDro scale for rating quality of randomized controlled trials. Phys Ther 2003;83:713-21.

29 Heidt RS Jr, Sweeterman LM, Carlonas RL, et al. Avoidance of soccer injuries with preseason conditioning. Am J Sports Med 2000;28:659-62.

30 Stovitz SD, Shrier I. Injury rates in team sport events: tackling challenges in assessing exposure time. Br I Sports Med 2012;46:960-3.

31 Meeuwisse WH, Love EJ. Athletic injury reporting. Development of universal systems. Sports Med 1997;24:184-204.

32 Hewett TE, Ford KR, Myer GD. Anterior cruciate ligament injuries in female athletes: part 2, a meta-analysis of neuromuscular interventions aimed at injury prevention. Am J Sports Med 2006;34:490-8.

33 Borenstein $\mathrm{M}$, Hedges LV, Higgins JPT, et al. Introduction to meta-analysis. Chichester, UK: John Wiley\& Sons, Ltd, 2009:33-9, 69-86.

34 Higgins JP, Thompson SG, Deeks JJ, et al. Measuring inconsistency in meta-analyses. BMJ 2003;327:557-60.

35 Rosenthal R. The file drawer problem and tolerance for null results. Psychol Bull 1979:86:638-41.

36 Begg CB, Mazumdar M. Operating characteristics of a rank correlation test for publication bias. Biometrics 1994;50:1088-101.

37 Sadoghi P, Von Keudell A, Vavken P. Effectiveness of anterior cruciate ligament injury prevention training programs. J Bone Joint Surg Am 2012;94:769-76.

38 Myer GD, Ford KR, McLean SG, et al. The effects of plyometric versus dynamic stabilization and balance training on lower extremity biomechanics. Am I Sports Med 2006:34:445-55.

39 Onate JA, Guskiewicz KM, Marshall SW, et al. Instruction of jump-landing technique using videotape feedback: altering lower extremity motion patterns. Am J Sports Med 2005;33:831-42.

40 Grindstaff TL, Hammill RR, Tuzson AE, et al. Neuromuscular control training programs and noncontact anterior cruciate ligament injury rates in female athletes: a numbers-needed-to-treat analysis. J Athl Train 2006;41:450-6.

41 Milner CE, Fairbrother JT, Srivatsan A, et al. Simple verbal instruction improves knee biomechanics during landing in female athletes. Knee 2012;19:399-403.

42 Stojanovic MD, Ostojlic SM. Preventing ACL injuries in team-sport athletes: a systematic review of training interventions. Res Sports Med 2012;20: 223-38.

43 Small K, Mc Naughton L, Matthews M. A systematic review into the efficacy of static stretching as part of a warm-up for the prevention of exercise-related injury. Res Sports Med 2008;16:213-31. 


\section{Review}

44 Jamtvedt G, Herbert RD, Flottorp S, et al. A pragmatic randomised trial of stretching before and after physical activity to prevent injury and soreness. $\mathrm{Br} / \mathrm{Sports} \mathrm{Med}$ 2010;44:1002-9.

45 Wilderman DR, Ross SE, Padua DA. Thigh muscle activity, knee motion, and impact force during side-step pivoting in agility-trained female basketball players. J Athl Train 2009;44:14-25.

46 Cortes N, Quammen D, Lucci $S$, et al. A functional agility short-term fatigue protocol changes lower extremity mechanics. I Sports Sci 2012:30: 797-805.
47 Hewett TE, Stroupe AL, Nance TA, et al. Plyometric training in female athletes. Decreased impact forces and increased hamstring torques. Am I Sports Med 1996;24:765-73.

48 Irmischer BS, Harris C, Pfeiffer RP, et al. Effects of a knee ligament injury prevention exercise program on impact forces in women. J Strength Cond Res 2004;18:703-7.

49 Markovic G, Mikulic P. Neuro-musculoskeletal and performance adaptations to lower-extremity plyometric training. Sports Med 2010;40:859-95.

50 Vescovi JD, Canavan PK, Hasson S. Effects of a plyometric program on vertical landing force and jumping performance in college women. Phys Ther Sport 2008;9:185-92. 